\title{
Molecular diagnostics in a tuberculous patient with clinical non response to standard treatment
}

\author{
TP Keerthirathne ${ }^{1}$, DK Weerasekera ${ }^{1}$, DN Magana-Arachchi ${ }^{1}$, NLA Dissanayake ${ }^{2}$
}

Sri Lankan Journal of Infectious Diseases 2016 Vol.6 (2):119-125

DOI: http://dx.doi.org/10.4038/sljid.v6i2.8103

\begin{abstract}
Rapid distinguishing of mycobacterial species and knowledge about their susceptibility is vital for the management of patients with pulmonary disease who are not responding to initial treatment as the mycobacteria have a spectrum of virulence and different susceptibilities to antibiotics. Most biochemical techniques used for species differentiation are laborious and time consuming. Hence molecular techniques are becoming an alternative to existing conventional testing. This study demonstrates the utility of molecular diagnostics for patients with mycobacterial infections who are not responding to initial anti TB therapy.
\end{abstract}

Key words: NTM, TB, MDR, SYBR Green, Real time PCR

\section{Introduction}

Tuberculosis (TB) is an infectious disease accountable for a leading number of deaths every year. ${ }^{1}$ Increasing prevalence of the multi-drug resistant (MDR) TB strains add to the global TB burden as it is difficult to manage and control disease caused by these strains which are resistant to the most effective anti-tuberculous drugs rifampin (RIF) and isoniazid (INH). ${ }^{2}$ Non-tuberculous mycobacteria (NTM) which include Mycobacterium species that are not members of the Mycobacterium tuberculosis complex (MTC) are ubiquitous environmental organisms mostly found in soil and water., ${ }^{3,4,5}$ Although NTM were initially thought to be non-pathogenic, they are now recognized as a cause of infections worldwide with an increasing prevalence. ${ }^{6}$ Drinking water systems and domestic tap water are also sources of potential contamination with NTM. $M$. intracelulare-M. avium complex (MAC) species have been found in both chlorine and chloramine disinfected potable water. ${ }^{7}$

Preliminary differentiation of NTM from M. tuberculosis (Mtb) can be done using susceptibility testing on separate media incorporated with either p-nitrobenzoic acid (PNB) or thiophen-2-carboxylic acid hydrazide (TCH) as NTM strains are resistant to PNB whereas Mtb are susceptible. On the other hand, Mtb strains are resistant to TCH but NTM are susceptible. ${ }^{6}$ As conventional detection methods using biochemical tests consume time, at present, molecular techniques have allowed great progress to be made in the rapid and accurate diagnosis of pulmonary infections caused by mycobacterial spp. This study reports the utility of molecular techniques in diagnosing tuberculous patients with clinical non response to standard treatment.

\footnotetext{
${ }^{1}$ National Institute of Fundamental Studies, Hantana Road, Kandy, Sri Lanka ${ }^{2}$ Respiratory and Chest Clinic, District General Hospital, Nuwara-Eliya, Sri Lanka

Address for correspondence: D. N. Magana-Arachchi, National Institute of Fundamental Studies, Hantana Road, Kandy, Sri Lanka Telephone: +94812232002 Email: cellbiology@ifs.as.lk
} 


\section{Methods}

In June 2014, a male estate worker from Nuwara Eliya district with an untreatable pulmonary infection was referred to the National Hospital for Respiratory diseases, Welisara, Sri Lanka by the Respiratory and Chest Clinic, District General Hospital, Nuwara-Eliya. Prior to transfer, a sputum sample collected from this patient for routine analysis was sent to the National Institute of Fundamental Studies, Kandy for microbiological analysis, including molecular diagnostic testing. The sample was subjected to $4 \% \mathrm{NaOH}$ treatment (Modified Petroff's method) and was concentrated by centrifugation (Revised National TB Control Programme Training Manual for Mycobacterium Tuberculosis Culture \& Drug Susceptibility Testing). The treated sample was cultured on two sets of Löwenstein-Jensen medium (L-J medium) i.e one set containing PNB and the other set containing TCH. Inoculations were carried out in triplicate and a control tube was also incubated under light and dark conditions at $28{ }^{\circ} \mathrm{C}$ and $37^{\circ} \mathrm{C}$. On detection of growth, acid fast bacilli were confirmed by light microscopic examination of the isolate after Ziehl-Neelson $(\mathrm{ZN})$ staining. ${ }^{8}$

Genomic DNA was extracted from the confirmed ZN positive isolates using the standard CTAB (N-Cetyl-N, N, N-trimethyl ammonium bromide) method. ${ }^{9}$ Conventional PCR assay was done with the use of Pt8 (5'-GTGCGGATGGTCGCAGAGAT-3') and Pt9 (5'CTCGATGCCCTCACGGTTCA-3') primers, ${ }^{10}$ and INS1 (5'-CGTGAGGGCA TCGAGG TGGC-3') and INS2 (5'GCGTAGGCGTCGGTGACAAA-3') primers $^{11}$ to confirm the presence of MTC. Primers targeting the internal transcribed spacers (ITs) of MTC and MCAG, the 16S rRNA genes of MAC, M. fortuitum group (MFG) and Mycobacterium genus were used for the SYBR green mediated real time multiplex, PCR assay. ${ }^{12}$ The slow and rapid growers were determined by the PCR assay which was conducted in two separate reactions where two primers specific for MTC and MAC were in reaction I and primers specific for MCAG and MFG were in reaction II. Additionally primers targeting the genus Mycobacterium were included in both reactions. Extracted DNA from M. tuberculosis $\mathrm{H}_{37} \mathrm{Rv}$ reference strain, $M$. phocaicum and $M$. intracellulare were used as standards for the SYBR green mediated real time PCR. Amplification was monitored by the measurement of the SYBR Green fluorescence. Subsequent to the cycling process, melting curves were generated by inclining the temperature from $60{ }^{\circ} \mathrm{C}$ to $95{ }^{\circ} \mathrm{C}$ at $0.2{ }^{\circ} \mathrm{C} / \mathrm{s}$. For the DNA sequencing the extracted DNA was amplified using universal primers ${ }^{12}$, F:TGGAGAGTTTGATCCTGGC TCAG and R: AAGGAGGTGATCCATC specific for $16 \mathrm{~S}$ rRNA gene. The resulting $1.5 \mathrm{~Kb}$ fragments were purified using Promega Wizard ${ }^{\circledR}$ SV gel / PCR clean up system as directed by the reagent manual and were sequenced in a commercial facility (Macrogen Inc. Korea).

Drug susceptibility testing was performed with freshly grown cultures using the agar proportion method (Revised National TB Control Programme Training Manual For Mycobacterium Tuberculosis Culture \& Drug Susceptibility Testing) and the disk diffusion method. ${ }^{13} \mathrm{INH}$ in the concentrations $0.2 \mu \mathrm{g} / \mathrm{ml}$ and $1.0 \mu \mathrm{g} / \mathrm{ml}$ and RIF in the concentration $0.2 \mu \mathrm{g} / \mathrm{ml}$ were tested using the agar proportion method. These drugs were incorporated in to the Middle Brook 7H11 (MB7H11) agar media enriched with the OADC supplement and the standard strain of H37Rv was used as the control. The same medium MB7H11 was used for the susceptibility testing for the drugs, Amikacin $(30 \mu \mathrm{g})$, Ciprofloxacin $(5 \mu \mathrm{g})$ and Clarithromycin $(15 \mu \mathrm{g})$ incorporated disks (Hardy Diagnostics, Santa Maria, CA). Simultaneously, the viability of the disks were tested using control strains of Escherichia coli ATCC 25922, Pseudomonas aeruginosa ATCC 27853 and Staphylococcus aureus ATCC 
25923 on Mueller-Hinton Agar medium. Susceptibility patterns of these organisms were compared as stated in Clinical and Laboratory Standards Institute. ${ }^{14}$

\section{Results}

The ZN stain confirmed the presence of acid fast bacilli which was observed as slender pink stained rods in the cultures observed (Fig.1) in TCH, PNB and the control L-J media indicating the presence of mycobacteria belonging to Mtb and NTM in the sputum sample of the patient who was suffering with the untreatable pulmonary infection.
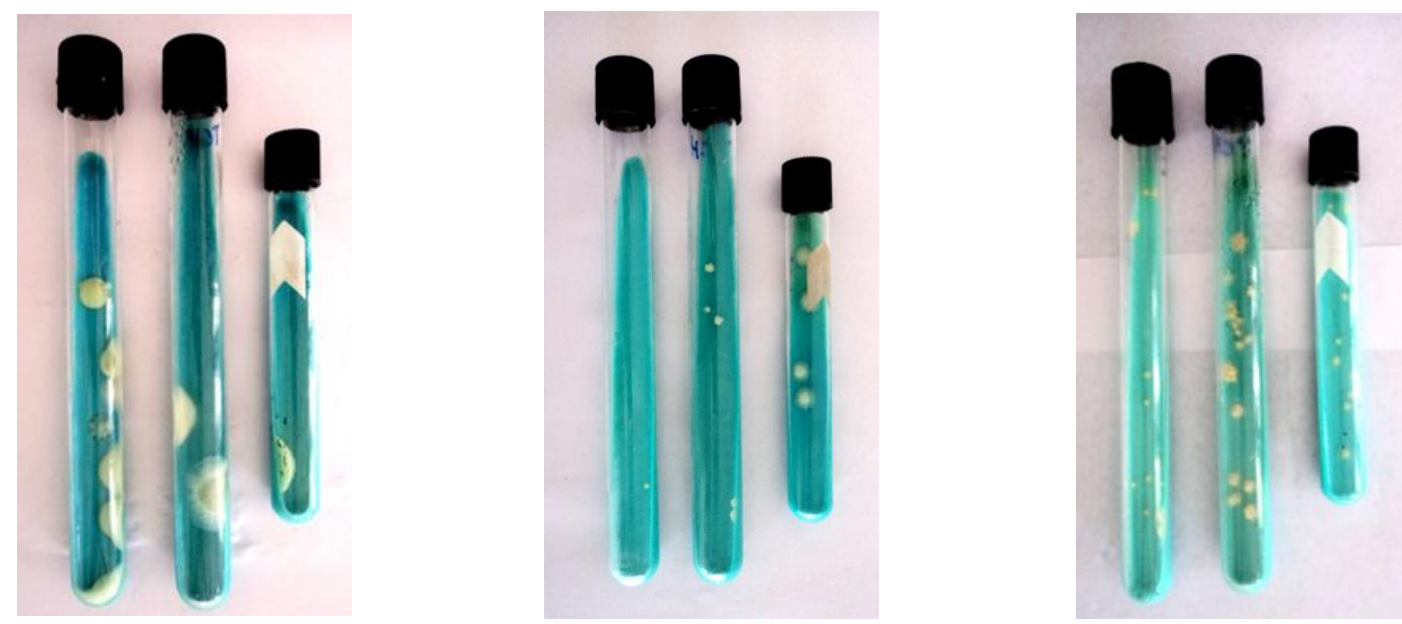

Fig. 1 - : Cultures observed after incubation under different environmental conditions.

A - Control L-J media incubated at $28^{\circ} \mathrm{C}$ under light conditions

B - L-J media incorporated with TCH incubated at $28^{\circ} \mathrm{C}$ under light conditions

C - L-J media incorporated with PNB incubated at $28^{\circ} \mathrm{C}$ under light conditions

D - Control L-J media incubated at $28^{\circ} \mathrm{C}$ under dark conditions

E - L-J media incorporated with TCH incubated at $28^{\circ} \mathrm{C}$ under dark conditions

F - L-J media incorporated with PNB incubated at $28^{\circ} \mathrm{C}$ under dark conditions

G - Control L-J media incubated at $37^{\circ} \mathrm{C}$

H - L-J media incorporated with TCH incubated at $37^{\circ} \mathrm{C}$

I - L-J media incorporated with PNB incubated at $37{ }^{\circ} \mathrm{C}$

Conventional PCR assay done with the use of Pt8/Pt9 and INS1/INS2 primers confirmed the presence of mycobacteria belonging to MTC. According to the SYBR Green mediated RTPCR result, the melting temperatures (Table 1) confirmed the presence of Mycobacterium genus and MCAG (Fig. 2).

Table 1 : Melting temperatures observed for the real time PCR assay

\begin{tabular}{ccccc}
\hline Reaction & $\begin{array}{c}\text { Amplicon } \\
\text { length }\end{array}$ & $\begin{array}{c}\text { Organism } \\
\text { identified }\end{array}$ & $\begin{array}{c}\text { RT-PCR } \\
\text { Result (C) }\end{array}$ & $\begin{array}{c}\text { Melting Temperature } \\
\text { given in literature } \\
\text { (C) }\end{array}$ \\
\hline I & 149 & $\begin{array}{c}\text { Mycobacterium } \\
\text { genus }\end{array}$ & 80.34 & $80.2-82.9$ \\
II & 128 & MCAG & 78.6 & $77.4 \pm 0.1$ \\
& & & 78.4 & \\
\hline
\end{tabular}

These results were confirmed by the Amplified fragment length after visualizing the bands on $2 \%$ electrophoresis gel (Fig. 3). Sequencing of the 16S rRNA gene further confirmed the 
presence of MCAG and the obtained sequences were deposited to the GenBank data base under the accession numbers KT371321, KT371322, KT371323. The disk diffusion antibiotic susceptibility testing conducted for MCAG isolate confirmed that the MCAG isolate was susceptible to all tested drugs. However Mtb strain was resistant to both INH and RIF, which explained the cause of the untreatable pulmonary infection.

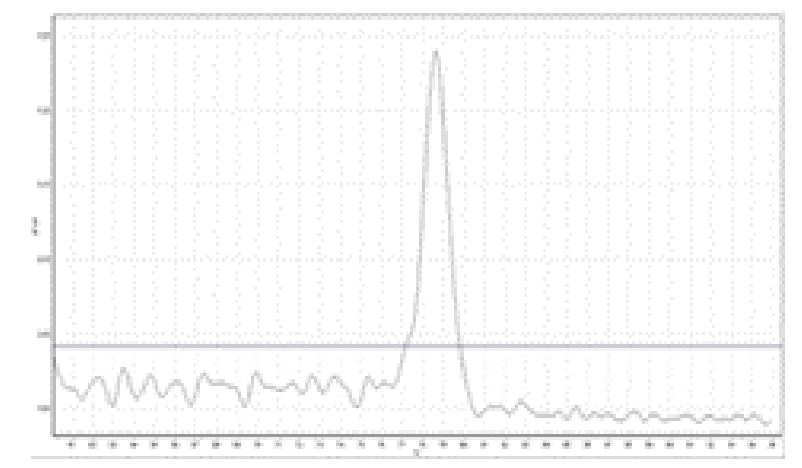

Fig. 2: Confirmation of the presence of MCAG by the melting curve generated by the SYBR Green mediated real time PCR

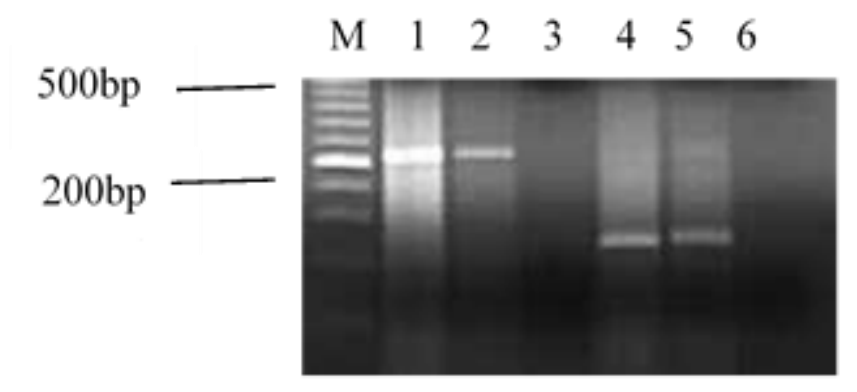

Fig 3: Agarose gel profile displaying the DNA fragments using Pt8/Pt9 and INS1/INS2 primers

M: 100 bp DNA ladder

Lane 1: DNA extracted from Control LJ at $37^{\circ} \mathrm{C}-$ for $\mathrm{Pt} 8 / 9$

Lane 2: DNA extracted from $\mathrm{TCH}$ at $37^{\circ} \mathrm{C}-$ for $\mathrm{Pt} 8 / 9$

Lane 3: Negative control - for Pt8/9

Lane 4: DNA extracted from Control $\mathrm{LJ}$ at $37^{\circ} \mathrm{C}-$ for INS1/2

Lane 5: DNA extracted from $\mathrm{TCH}$ at $37^{\circ} \mathrm{C}-$ for INS1/2

Lane 6: Negative control- for INS1/2

\section{Discussion}

Co-infections with Mtb and NTM have been previously reported. ${ }^{15}$ However, data on the clinicai importance of such co-infections is scarce. The presence of NTM in patients with TB can have a considerable influence on clinical management and misdiagnosis of pulmonary diseases due to the presence of both Mtb and NTM can lead to various complications. NTM are ubiquitous in nature. Therefore isolation of NTM from a single sample of sputum is not generally identified as evidence of an infection due to NTM, especially when the identified 
NTM is a rapid grower since it could also be due to either contamination or colonization. This is especially important when a significant pathogen is present in the same sample which could lead to masking of the pathogen by the NTM.

According to statistics of the World Health Organization (WHO), only around 10\% of MDRTB cases in the world are detected. Though culture is the gold standard for confirmation of a TB diagnosis, due to slow growth of Mtb, the isolation of the organism exceeds three weeks, which hinders confirmation of the diagnosis. Identification of isolates to species level using standard methods is laborious and time consuming. ${ }^{17,18}$ Hence WHO has endorsed the use of molecular methods for the detection of TB and drug-resistant TB as a rapid alternative to culture-based systems. ${ }^{19,20}$ Some of these tests such as line probe assays are commercially available and the results could be given within two days although feasibility of using these assays in low and middle income countries are dependent on consumables, infrastructure, training, quality assurance and other requirements. ${ }^{19,21}$ Real time PCR (qPCR) has overcome the disadvantages of traditional culture; by improving the precision, reproducibility and quality control processes, reducing contamination and shortening the time taken for laboratory analysis to three or four days. ${ }^{18}$ By using validated PCR techniques ${ }^{11,12}$ the identification of organisms into species level has also become a quick and simple task.

In this study both conventional culture techniques and the molecular techniques of multiplex qPCR and DNA sequencing were exploited for the identification and differentiation of the mycobacteria present in the sputum and antibiotic susceptibility testing which demonstrated the usefulness of the combined approach. The SYBR Green mediated real time PCR assay described can be used to identify most pathogenic mycobacteria ${ }^{12}$ in two parallel reactions, which include MTC and MAC in one reaction and MCAG and MFG in the other reaction which helps in identifying slowly growing and rapidly growing mycobacteria respectively. Addition of primers targeting the Mycobacterium genus was useful in identifying the mycobacterial species which were different from the target organisms. The results obtained in the qPCR were confirmed by the results of the DNA sequencing done in a commercial facility, which displayed the accuracy of the qPCR technique. As such, Reference Laboratories can perform a cost analysis on this in-house real time PCR technique in comparison with the WHO endorsed techniques before incorporating this methodology into practice.

\section{Conclusion}

The results indicate that combined application of real-time PCR and conventional culture techniques with drug susceptibility, is an effective approach to enable accurate diagnosis of mycobacterial infections from sputum samples. Utilizing these combined applications can improve the treatment strategies and the overall management of patients with mycobacterial infections who are not responding to initial anti TB therapy.

\section{Conflicts of Interests}

The authors declare that they have no competing interests

\section{Acknowledgement}

The authors gratefully acknowledge the National Research Council, Sri Lanka, Grant Number 11-059 for providing the Real-Time PCR instrument. 


\section{References}

1. Moon SH, Kim EJ, Tomono J, et al. Detection of Mycobacterium tuberculosis complex in sputum specimens using a loop-mediated isothermal amplification (LAMP) assay in Korea. Journal of Medical Microbiology. 2015; 64:1335-1340. doi : http://dx.doi.org/10.1099/jmm.0.000164

2. Mulisa G, Workneh $\mathrm{T}$, Hordofa $\mathrm{N}$, et al. Multi-drug resistant Mycobacterium tuberculosis and associated risk factors in the Oromia region of Ethiopia. International Journal of Infectious Diseases. 2015; 39:57-61. doi : http://dx.doi.org/10.1016/j.ijid.2015.08.013

3. Kim JK, Rheem I. Identification and distribution of nontuberculous mycobacteria from 2005 to 2011 in Cheonan, Korea. Tuberculosis and Respiratory Diseases. 2013; 74(5):215-21. http://dx.doi.org/10.4046/trd.2013.74.5.215

4. Pauls RJ, Turenne CY, Wolfe JN, Kabani A. A high proportion of novel mycobacteria species identified by $16 \mathrm{~S}$ rDNA analysis among slowly growing AccuProbe-negative strains in a clinical setting. American Journal of Clinical Pathology. 2003; 120(4):560-6. doi : http://dx.doi.org/10.1309/VF40-1U7H-7DHE-OFRE

5. Asiimwe BB, Bagyenzi GB, Ssengooba W, et al. Species and genotypic diversity of non-tuberculous mycobacteria isolated from children investigated for pulmonary tuberculosis in rural Uganda. BMC Infectious Diseases. 2013; 13:88.

doi : http://dx.doi.org/10.1186/1471-2334-13-88

6. Giampaglia CM, Martins MC, Inumaru VT, et al. Evaluation of a rapid differentiation test for the Mycobacterium tuberculosis complex by selective inhibition with rho-nitrobenzoic acid and thiophene-2-carboxylic acid hydrazide. The International Journal of Tuberculosis and Lung Diseases. 2005; 9(2):206-9.

7. Whiley H, Keegan A, Fallowfield H, Bentham R. Detection of Legionella, L. pneumophila and Mycobacterium avium complex (MAC) along potable water distribution pipelines. International Journal of Environmental Research and Public Health. 2014; 11(7):7393-405. doi : http://dx.doi.org/10.3390/ijerph110707393

8. Koch ML and Cote RA. Comparisons of fluorescence microscopy with ZiehlNeelsen stain for demonstration of acid-fast bacilli in smear preparations and tissue sections. American Review of Respiratory Disease. 1965; 91(2):283-284. doi : http://dx.doi.org/10.1164/arrd.1965.91.2.283

9. Somerville W, Thibert L, Schwartzman K, Behr MA. Extraction of Mycobacterium tuberculosis DNA: a question of containment. Journal of Clinical Microbiology. 2005; 43(6):2996-7. doi : http://dx.doi.org/10.1128/JCM.43.6.2996-2997.2005

10. Kox LF, Rhienthong D, Miranda AM, et al. A more reliable PCR for detection of Mycobacterium tuberculosis in clinical samples. Journal of Clinical Microbiology. 1994; 32(3):672-8.

11. Kolk AH, Schuitema AR, Kuijper S, et al. Detection of Mycobacterium tuberculosis in clinical samples by using polymerase chain reaction and a nonradioactive detection system. Journal of Clinical Microbiology. 1992; 30(10):2567-75.

12. Richardson ET, Samson D, Banaei N. Rapid Identification of Mycobacterium tuberculosis and nontuberculous mycobacteria by multiplex, real-time PCR. Journal of Clinical Microbiology.. 2009; 47(5):1497-502.

doi : http://dx.doi.org /10.1128/JCM. 01868-08 
13. Wallace RJ, Jr., Dalovisio JR, Pankey GA. Disk diffusion testing of susceptibility of Mycobacterium fortuitum and Mycobacterium chelonei to antibacterial agents. Antimicrobial Agents and Chemotherapy. 1979; 16(5):611-4. doi : http://dx.doi.org /10.1128/AAC.16.5.611

14. $\mathrm{Yu} \mathrm{XL}, \mathrm{Lu} \mathrm{L}, \mathrm{Chen} \mathrm{GZ}$, et al. Identification and characterization of nontuberculous mycobacteria isolated from tuberculosis suspects in Southern-central China. PloS one. 2014; 9(12):e114353. doi : http://dx.doi.org/10.1371/journal. pone. 0114353

15. Maiga M, Siddiqui S, Diallo S, et al. Failure to recognize nontuberculous mycobacteria leads to misdiagnosis of chronic pulmonary tuberculosis. PloS one. 2012; 7(5):e36902. doi : http://dx.doi.org/10.1371/journal.pone.0036902

16. WHO: Multidrug and Extensively drug-resistant TB: 2010 Global Report on Surveillance andResponse;2010. http://whqlibdoc.who.int/publications /2010 19789241 599191_eng.pdf

17. Telenti A, Marchesi F, Balz M, et al. Rapid identification of mycobacteria to the species level by polymerase chain reaction and restriction enzyme analysis. Journal of Clinical Microbiology. 1993; 31:175-178.

18. Sales ML, Fonseca AA, Júnior, Orzil L, et al. Validation of a real-time PCR assay for the molecular identification of Mycobacterium tuberculosis. Brazilian Journal of Microbiology. 2014; 45(4): 1363-1369.

doi : http://dx.doi.org/10.1590/S1517-83822014000400029

19. Molecular Line Probe Assays for rapid screening of patients at risk of multidrugresistant tuberculosis. http://www.who.int/tb/features_archive/policy_statement.pdf

20. Automated real-time nucleic acid amplification technology for rapid and simultaneous detection of tuberculosis and drug resistant tuberculosis: Policy Statement. http://apps.who.int/iris/bitstream/10665/44586/1/9789241501545eng. pdf

21. Albert H, Bwanga F, Mukkada S. et al. Rapid screening of MDR-TB using molecular Line Probe Assay is feasible in Uganda. BMC Infectious Diseases. 2010; 10: 41. doi : http://dx.doi.org/10.1186/1471-2334-10-41 